\title{
BMJ Open Investigating the association between prepregnancy body mass index and adverse pregnancy outcomes: a large cohort study of 536098 Chinese pregnant women in rural China
}

\author{
Yi Pan, ${ }^{1}$ Shikun Zhang, ${ }^{2}$ Qiaomei Wang, ${ }^{2}$ Haiping Shen, ${ }^{2}$ Yiping Zhang, ${ }^{2}$ \\ Yuanyuan Li, ${ }^{3}$ Donghai Yan, ${ }^{2}$ Lizhou Sun ${ }^{1}$
}

To cite: Pan Y, Zhang S, Wang $Q$, et al. Investigating the association between prepregnancy body mass index and adverse pregnancy outcomes: a large cohort study of 536098 Chinese pregnant women in rural China. BMJ Open 2016;6: e011227. doi:10.1136/ bmjopen-2016-011227

- Prepublication history for this paper is available online. To view these files please visit the journal online (http://dx.doi.org/10.1136/ bmjopen-2016-011227).

YP and SZ contributed equally.

Received 20 January 2016 Revised 24 June 2016 Accepted 28 June 2016

CrossMark

For numbered affiliations see end of article.

Correspondence to Professor Lizhou Sun; lizhousun.nj@gmail.com

\section{ABSTRACT}

Objective: Unhealthy maternal weight before pregnancy increases the risk of various adverse pregnancy outcomes. We conducted a nutrition survey to provide baseline data on the prepregnant nutritional status of mothers in order to better understand the association between prepregnancy maternal body mass index (BMI) and adverse pregnancy outcomes.

Design: A large, prospective, population-based cohort study.

Setting: Data from the National Free Preconception Health Examination Project (NFPHEP) in China during 2010-2012.

Participants: 536098 pregnant women out of 2120131 were evaluated.

Primary and secondary outcome measures: The primary adverse pregnancy outcomes included preterm birth (PTB), low birth weight (LBW), spontaneous miscarriage (SM), ectopic pregnancy (EP) and stillbirth (SB). $A \chi^{2}$ test was used to compare the prevalence of each BMI category during 2010-2012. Univariable and multiple logistic regression analyses were performed to assess the association between prepregnancy BMI and various adverse pregnancy outcomes.

Results: Between 2010 and 2012, the average BMI decreased from 21.31 to 21.16 , while underweight prevalence increased from $10.40 \%$ to $14.14 \%$. An age-stratified subgroup analysis indicated that the underweight prevalence increased from $13.52 \%$ to $17.02 \%$ among women aged $21-24$ and from $10.72 \%$ to $13.71 \%$ among women aged $25-34$. Overweight prevalence increased from $9.84 \%$ to $10.75 \%$ (25-34 years) and from $17.10 \%$ to $19.20 \%$ (3549 years). Obesity prevalence increased from $2.17 \%$ to $2.42 \%$ and from $4 \%$ to $4.2 \%$ among women aged 25-34 and 35-49 respectively. Prepregnancy underweight was associated with PTB, LBW and SM; overweight women had an increased risk of LBW; obese women had a higher risk of LBW, SM, EP and SB.

Conclusions: While the average prepregnancy BMI decreased, the prevalence of underweight individuals in a very large population significantly increased.

\section{Strengths and limitations of this study}

- A 3-year prospective study from 2010 to 2012 revealed the trend of prepregnancy body mass index (BMI), as well as the relationship between extremes of the maternal BMI and adverse pregnancy outcomes.

- This is the largest nationwide, population-based cohort study over the past 10 years on pregnancy outcomes in relation to prepregnancy BMI in China.

- The measurement of prepregnancy BMI might be less accurate if conception occurred towards the end of 6 months after enrolment.

- The majority of surveyed women in the NFPHEP were from China's rural areas, and thus, the conclusions made in this study are most pertinent to this region.

The abnormal prepregnancy BMls were associated with increased risks of adverse pregnancy outcomes. Most notably, underweight prepregnant women appeared to be at a greater risk of developing adverse pregnancy outcomes in China's rural areas.

\section{INTRODUCTION}

Prepregnancy body mass index (BMI) is believed to be an important indicator of pregnancy outcomes. ${ }^{12}$ Being underweight or overweight prior to pregnancy may increase risk for pregnancy complications. The ideal fertility weight and prepregnancy BMI for a healthy pregnancy and delivery are still under investigation.

The prevalence of overweight and obesity has increased at an alarming rate among women in many countries, particularly in developed countries in recent decades. In the USA, a 2009-2010 survey indicated that 55.8\% of women of childbearing age (20-39 years) 
were overweight or obese, defined as having a BMI of 25 or higher. ${ }^{3}$ Overweight or obesity before pregnancy is associated with an increased risk of maternal and neonatal complications, such as gestational hypertension, preeclampsia, gestational diabetes, premature rupture of membranes, prematurity, macrosomia and shoulder dystocia. ${ }^{4}$ Similarly, maternal underweight has been shown to increase risk for adverse perinatal outcomes, including preterm birth (PTB), low birth weight (LBW) and intrauterine growth restriction. ${ }^{5}$

However, the conclusions drawn by some studies investigating the associations between prepregnancy BMI and adverse pregnancy outcomes such as PTB appear to be inconsistent. It was reported that the obese have a significantly elevated risk for early PTB (<32 weeks), ${ }^{1} 67$ but other studies contradicted this result, suggesting that overweight and obesity could exert a protective effect against PTB. ${ }^{8}{ }^{9}$ One explanation for such inconsistencies could be that the majority of data available for prepregnancy BMI was not collected using methods with a rigorous anthropometric measurement, but relied on recollection or self-reporting. It is inevitable that underreporting or over-reporting their weight and height may have occurred. Owing to the bias of self-reported data, researchers might make measurement errors and misclassify prepregnancy BMI categories, ${ }^{10}$ hence leading to inconsistent conclusions.

The association between prepregnancy BMI and adverse pregnancy outcomes in China is more complex because of the geographic imbalance of China's economy and large population. China recommends using lower BMI cut-off values to define normal weight (18.5$\left.23.9 \mathrm{~kg} / \mathrm{m}^{2}\right)$, overweight $\left(24-27.9 \mathrm{~kg} / \mathrm{m}^{2}\right)$ and obesity $\left(\geq 28 \mathrm{~kg} / \mathrm{m}^{2}\right)$, while the WHO has slightly different definitions: healthy $\left(18.5-24.9 \mathrm{~kg} / \mathrm{m}^{2}\right)$, overweight (25$\left.29.9 \mathrm{~kg} / \mathrm{m}^{2}\right)$ and obesity $\left(\geq 30 \mathrm{~kg} / \mathrm{m}^{2}\right)$. In spite of some correlational studies focusing on regional surveillance, ${ }^{11-}$ 13 there is no nationwide survey in China. We conducted this large population-based cohort study to provide updated baseline data for the prepregnancy nutritional status among women of childbearing ages in rural areas and to assess the association between prepregnancy BMI and adverse pregnancy outcomes. It is important for policymakers to produce practical and stratified BMI classification guidelines in order to reduce the risk of negative mother/infant birth outcomes.

\section{METHODS}

\section{Participants}

The National Health and Family Planning Commission and the Ministry of Finance in China launched a project in 2010. This project provided free preconception health examinations in rural areas to married couples that planned a pregnancy within the next 6 months. A total of 2120131 Chinese women between 21 and 49 years old from 220 counties from 31 of the 33 mainland provinces of China were enrolled in the National
Free Preconception Health Examination Project (NFPHEP) from 1 January 2010 to 31 December 2012. Free medical examinations and preconception counselling services by well-trained local community health workers and medical managements during pregnancy by obstetricians were provided to all enrolled women, among which 603262 women had pregnancy outcomes by 31 December 2012. A web-based electronic data collection system for data entry was created and maintained by the NFPHEP Office. Women with missing data that were critical for statistical analysis and extreme value were excluded in the subsequent analysis. Thus, the final study population was 536098 women with pregnancy outcomes. Each participant received a copy of an information letter, read it, and agreed to an informed consent agreement. The detailed information of the NFPHEP was recorded elsewhere. ${ }^{14} 15$

\section{Study variables}

Prepregnancy BMI, defined as the body weight in kilograms divided by the square of the height in metres $(\mathrm{kg} /$ $\mathrm{m}^{2}$ ), was obtained from the prepregnancy examinations. A cooperative meta-analysis organised by the Working Group on Obesity in China (WGOC), International Life Sciences Institute (ILSI) indicated that BMI of $24-28 \mathrm{~kg} / \mathrm{m}^{2}$ was defined as overweight. BMI of $28 \mathrm{~kg} / \mathrm{m}^{2}$ and above that may identify the risk factors with specificity around $90 \%$ was recommended as the cut-off point for obesity in China. ${ }^{16}$ Therefore, we adopted the following cut-off points: underweight $\left(<18.5 \mathrm{~kg} / \mathrm{m}^{2}\right)$, normal weight $\left(18.5-23.9 \mathrm{~kg} / \mathrm{m}^{2}\right)$, overweight $\left(24-27.9 \mathrm{~kg} / \mathrm{m}^{2}\right)$ and obesity $\left(\geq 28 \mathrm{~kg} / \mathrm{m}^{2}\right)$. We used standardised procedures to ensure high data quality when obtaining height and weight measurements. Gestational age at birth was calculated as the number of completed weeks of gestation from the first day of the last menstrual period to the date of delivery, or based on the expected date of parturition according to ultrasound scanning. We also analysed additional risk factors: maternal age, ethnicity, educational level, occupation, smoking, alcohol intake, a maternal history of pregnancy, PTB, stillbirth (SB), birth defects and spontaneous miscarriage (SM).

\section{Adverse pregnancy outcomes}

Information regarding adverse pregnancy outcomes was collected from medical records, including the prenatal visits and delivery records. In this study, PTB was defined as a delivery earlier than 37 gestation weeks; LBW was defined as birth weight of $<2500 \mathrm{~g}$; SM was defined as the involuntary termination of a non-viable intrauterine pregnancy before 28 weeks of gestation; and SB was defined as fetal death at 20 weeks of gestation or more. All pregnancy outcomes were identified according to the clinical diagnosis by the caring obstetrician, not self-reported.

\section{Statistical analysis}

Student's t-test and a one-way analysis of variance (ANOVA) were employed to compare two or multiple 
groups, with respect to continuous variables. A $\chi^{2}$ test was used to assess the trend of prepregnancy maternal BMI. Univariable and multivariable logistic regressions were used to test the association between maternal prepregnancy BMI and each adverse pregnancy outcome with normal BMI group as a reference point. Adjusted ORs (aORs) and 95\% CI were obtained by using the multiple logistic regression model, with adjustment for maternal age, ethnicity, educational level, occupation, smoking, alcohol intake, a previous history of pregnancy, PTB, SB, birth defects and SM. All the raw data were analysed using R statistical package. The result was considered statistically significant when $\mathrm{p}<0.05,0.01,0.001$, or 0.0001 .

\section{RESULTS}

The sociodemographic characteristics of maternal age, ethnicity, education level and occupation in the 2120131 women of childbearing age (21-49 years) enrolled in the NFPHEP are described in table 1 . The majority of participants (1 395 926, 65.84\%) registered during 2010-2012 were between 25 and 34 years of age. In total of 1482723 (70.71\%) participants had an education level of junior high school level or below, and 1595178 (76.62\%) were farmers from China's rural areas.

\section{Prevalence of abnormal prepregnancy BMI in women} of childbearing age during 2010-2012

After excluding incomplete data points (no BMI data available), 1981225 records remained (table 2). The results suggested a decrease in average BMI among participants, from 21.31 to 21.16, between 2010 and 2012, while the prevalence of underweight, in a large population, continuously increased from $10.40 \%$ to $14.14 \%$ $(\mathrm{p}<0.0001)$ (figure 1). From 2010 to 2012, there were slight variations in the prevalence of overweight and obesity among the total population. An analysis of age-stratified subgroups showed that the prevalence of underweight women increased from $13.52 \%$ to $17.02 \%$ in the age group of $21-24(\mathrm{p}<0.0001)$ and from $10.72 \%$ to $13.71 \%$ in the age group of $25-34(\mathrm{p}<0.0001)$. The prevalence of overweight women increased from $9.84 \%$ to $10.75 \%$ in the age group of $25-34(p<0.0001)$ and from $17.10 \%$ to $19.20 \%$ ( $\mathrm{p}<0.0001)$ in the age group of $35-49$ years, and obesity increased from $2.17 \%$ to $2.42 \%$ $(\mathrm{p}<0.0001)$ and from $4 \%$ to $4.2 \% \quad(\mathrm{p}<0.0001)$ among women aged 25-34 and 35-49, respectively, during the period 2010-2012 (table 3 and figure 2).

\section{Characteristics of $\mathbf{5 3 6} 098$ pregnant participants}

Before 31 December 2012, 603262 women had achieved pregnancy outcomes. According to the exclusion principle, 536098 were eligible for the inclusion in the association analysis between prepregnancy BMI and adverse pregnancy outcomes. Prior to the assessment, we characterised pregnant women in more details during the years 2010-2012 on age, ethnicity, occupation, education level, smoking, alcohol intake, maternal history of pregnancy, PTB, SB, SM and birth defects. As shown in table 4, about half of the pregnant women were aged between 25 and $29(49.6 \%)$. In total $65.6 \%$ of them only graduated from junior middle school. Most of them were of Han ethnicity $(94.6 \%)$, farmers $(76.4 \%)$, non-smokers $(99.7 \%)$, nondrinkers $(97 \%)$, and had no history of pregnancy $(65.6 \%)$, PTB $(99.8 \%)$, SB (99.2\%), SM (97.3\%) or birth defects $(99.7 \%)$. Prepregnancy BMI was significantly higher among women who were older, while women who were more educated showed a significantly lower BMI $(\mathrm{p}<0.0001$, table 4). Smokers, alcohol drinkers or women with either history of pregnancy, PTB, SB, SM and birth defects were more likely to be overweight. The one-way ANOVA or Student's t-test indicated that the difference between groups in each variable was statistically significant $(\mathrm{p}<0.0001$, table 4$)$.

\begin{tabular}{|c|c|c|c|c|}
\hline & $\begin{array}{l}\text { 2010-2012 } \\
\text { n (\%) }\end{array}$ & $\begin{array}{l}2010 \\
n(\%)\end{array}$ & $\begin{array}{l}2011 \\
\text { n (\%) }\end{array}$ & $\begin{array}{l}2012 \\
\text { n (\%) }\end{array}$ \\
\hline \multicolumn{5}{|l|}{ Age, years } \\
\hline $21-24$ & 501973 (23.68) & 43833 (12.09) & 190202 (20.88) & 267938 (31.65) \\
\hline $25-34$ & $1395926(65.84)$ & $268656(74.11)$ & $613740(67.37)$ & $513530(60.66)$ \\
\hline $35-49$ & 222232 (10.48) & 50019 (13.80) & 107099 (11.75) & $65114(7.69)$ \\
\hline \multicolumn{5}{|l|}{ Ethnicity } \\
\hline Han & 1924868 (91.41) & 338478 (93.58) & $823942(90.86)$ & 762448 (91.06) \\
\hline Others & 180900 (8.59) & 23222 (6.42) & 82847 (9.14) & 74831 (8.94) \\
\hline \multicolumn{5}{|l|}{ Educational level } \\
\hline Junior high school or below & 1482723 (70.71) & 264668 (73.65) & 654438 (72.53) & 563617 (67.48) \\
\hline Senior high school & 385610 (18.39) & 65884 (18.33) & $155142(17.2)$ & 164584 (19.71) \\
\hline College or higher & 228447 (10.90) & 28845 (8.02) & $92660(10.26)$ & $106942(12.81)$ \\
\hline \multicolumn{5}{|l|}{ Occupation } \\
\hline Farmers & 1595178 (76.62) & 272014 (76.22) & 699626 (78.21) & $623538(75.08)$ \\
\hline Factory workers & $186303(8.95)$ & $39782(11.15)$ & $69583(7.78)$ & $76938(9.26)$ \\
\hline Others & 300483 (14.43) & 45084 (12.63) & $125388(14.01)$ & $130011(15.66)$ \\
\hline
\end{tabular}


Table 2 Prevalence of each body mass index (BMI) category in women of childbearing age during 2010-2012 in total

\begin{tabular}{|c|c|c|c|c|c|}
\hline $\begin{array}{l}\text { BMI category } \\
\left(\mathrm{kg} / \mathrm{m}^{2}\right)\end{array}$ & $\begin{array}{l}\text { 2010-2012 } \\
\text { n (\%) }\end{array}$ & $\begin{array}{l}2010 \\
\text { n (\%) }\end{array}$ & $\begin{array}{l}2011 \\
n(\%)\end{array}$ & $\begin{array}{l}2012 \\
\text { n (\%) }\end{array}$ & p Value* \\
\hline$<18.5$ & $261671(13.21 \%)$ & 31649 (10.40\%) & 115863 (13.32\%) & 114159 (14.14\%) & $<0.0001$ \\
\hline $18.5-23.9$ & 1454678 (73.42\%) & 233100 (76.60\%) & 633325 (72.81\%) & 588253 (72.88\%) & $<0.0001$ \\
\hline $24-27.9$ & 217864 (11.00\%) & 32435 (10.66\%) & 99445 (11.43\%) & 85984 (10.65\%) & $<0.0001$ \\
\hline$\geq 28$ & $47012(2.37 \%)$ & 7123 (2.34\%) & $21154(2.43 \%)$ & $18735(2.32 \%)$ & $<0.0001$ \\
\hline $\bar{T}$ Total & $1981225(100 \%)$ & 304307 (15.36\%) & 869787 (43.90\%) & $807131(40.74 \%)$ & $<0.0001$ \\
\hline Mean BMI & 21.225 & 21.311 & 21.255 & 21.159 & $<0.0001$ \\
\hline$(95 \% \mathrm{Cl})$ & (21.221 to 21.228 ) & (21.301 to 21.320$)$ & (21.249 to 21.261$)$ & (21.153 to 21.165 ) & $<0.0001$ \\
\hline
\end{tabular}

${ }^{*} \chi^{2}$ test for comparing the prevalence of each BMI category in different years.

\section{Logistic regression analysis}

To evaluate the association between prepregnancy BMI and adverse pregnancy outcome among the 536098 surveyed women, we applied a univariable or multivariable logistic regression model. The percentages of adverse pregnancy outcomes and the aORs according to BMI are shown in table 5. The reference group was the group of women with a BMI of $18.5-23.9 \mathrm{~kg} / \mathrm{m}^{2}$.

PTB occurred in $6200(\sim 1.2 \%)$ of 536098 eligible pregnancies. Underweight (crude OR, 1.16 (95\% CI 1.08 to 1.24$), \mathrm{p}<0.0001$ ) and obese (crude OR, 1.21 (95\% CI 1.02 to 1.44 ), $\mathrm{p}<0.05$ ) women were more likely to give premature birth. After the adjustment for potential confounding factors, the aORs for PTB were 1.16 (95\% CI 1.08 to 1.25 ) and 1.18 (95\% CI 0.99 to 1.4 ), respectively. Prepregnancy underweight was significantly associated with the increased risk for PTB, while obesity only had a marginally significant risk (table 5).

In comparison with women who have normal prepregnancy BMI, women with other abnormal BMI categories were more likely to deliver a LBW infant. The aORs associated with the risk for giving birth to a LBW infant were 1.57 (95\% CI 1.4 to 1.57$)$ in underweight women, 1.22 (95\% CI 1.05 to 1.42$)$ in overweight women and 1.6 (95\% CI 1.2 to 2.12 ) in obese women. Similarly, attributing the outcomes to the abnormal BMI, there was an increased risk of SM in underweight women (aOR 1.11; $95 \%$ CI 1.06 to 1.17 ), overweight women (aOR 1.02; 95\% CI 0.97 to 1.08 ) and obese women (aOR 1.13; $95 \%$

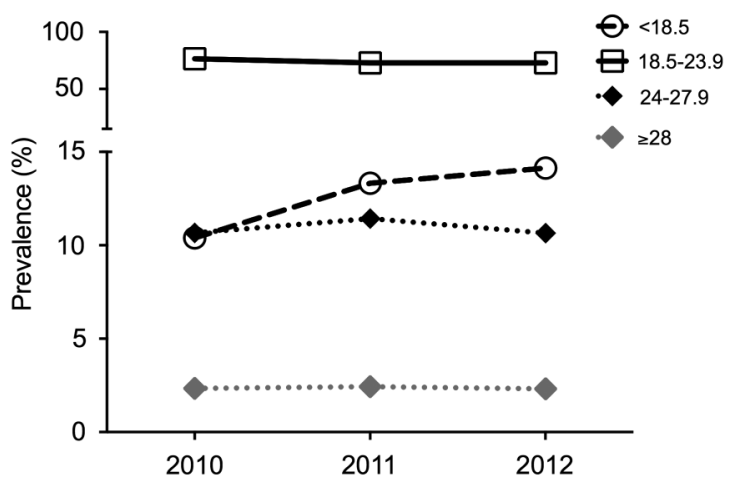

Figure 1 Trends of prepregnancy body mass index among women of childbearing age during 2010-2012.
CI 1.02 to 1.26$)$. However, significant differences were only found among the underweight and obese groups (table 5).

Despite being underweight (aOR 1.09; 95\% CI 0.82 to 1.45 ) and obese women (aOR $1.78 ; 95 \%$ CI 1.13 to 2.81) having an elevated risk of ectopic pregnancy (EP), the statistical analysis indicated a significant difference in obesity category $(p<0.0130)$. Unexpectedly, being overweight imparted protection against EP (aOR 0.74; $95 \%$ CI 0.53 to 1.04$)$. However, the difference was not significant (table 5).

Table 5 also revealed that SB was much more common in overweight and obese women than in women with a normal BMI. Obesity was significantly correlated with elevated risk for SB (aOR 1.59; 95\% CI 1.18 to 2.15). There was no correlation between underweight and SB in this study.

\section{DISCUSSION}

\section{Comparison with other studies}

In the USA, the prevalence of prepregnancy obesity has increased from $17.6 \%$ in 2003 to $20.5 \%$ in 2009, data of which were released from the Pregnancy Risk Assessment Monitoring System (PRAMS) ${ }^{17}$ The nationwide nutrition survey in China also showed that the prevalence of overweight women aged 18-44 increased from 16.8 to $21.8 \%$, and the prevalence of obesity increased from $3.1 \%$ to $6.1 \%$ during the years 1992 2002. ${ }^{18}$ Our study showed that the rates of overweight and obesity are much lower and the prevalence of underweight women of childbearing age is higher than those in the previous reports. Examination of these data led us to attribute these differences to the fact that the participants in our study are mainly from the rural areas and are at relatively younger ages. The reasons for the increasing prevalence of underweight prepregnant women remain elusive and warrant further investigation.

\section{Proposed mechanisms between prepregnancy BMI and adverse pregnancy outcomes}

The influence of maternal prepregnancy BMI on the incidence of PTB has been explored previously. Low prepregnancy BMI has been consistently reported as a 
Table 3 Prevalence of each body mass index (BMI) category in age-stratified groups during 2010-2012

\begin{tabular}{|c|c|c|c|c|c|}
\hline BMI category $\left(\mathrm{kg} / \mathrm{m}^{2}\right)$ & $\begin{array}{l}\text { 2010-2012 } \\
\text { n (\%) }\end{array}$ & $\begin{array}{l}2010 \\
\text { n (\%) }\end{array}$ & $\begin{array}{l}2011 \\
\text { n (\%) }\end{array}$ & $\begin{array}{l}2012 \\
\text { n (\%) }\end{array}$ & p Value* \\
\hline \multicolumn{6}{|l|}{$21-24$ years } \\
\hline$<18.5$ & $78923(16.38 \%)$ & 5398 (13.52\%) & $29669(16.09 \%)$ & 43856 (17.02\%) & $<0.0001$ \\
\hline $18.5-23.9$ & 354143 (73.47\%) & 30533 (76.49\%) & 135764 (73.64\%) & $187846(72.89 \%)$ & $<0.0001$ \\
\hline $24-27.9$ & 40959 (8.50\%) & $3381(8.47 \%)$ & 15907 (8.63\%) & 21671 (8.41\%) & 0.0360 \\
\hline$\geq 28$ & 7939 (1.65\%) & $606(1.52 \%)$ & 3015 (1.64\%) & 4318 (1.68\%) & 0.0620 \\
\hline \multicolumn{6}{|l|}{$25-34$ years } \\
\hline$<18.5$ & 170839 (13.21\%) & $23862(10.72 \%)$ & $80151(13.75 \%)$ & $66826(13.71 \%)$ & $<0.0001$ \\
\hline $18.5-23.9$ & $954314(73.82 \%)$ & $171923(77.27 \%)$ & 426107 (73.07\%) & $356284(73.12 \%)$ & $<0.0001$ \\
\hline $24-27.9$ & 137529 (10.64\%) & $21893(9.84 \%)$ & $63253(10.85 \%)$ & $52383(10.75 \%)$ & $<0.0001$ \\
\hline$\geq 28$ & 30209 (2.33\%) & $4838(2.17 \%)$ & 13564 (2.33\%) & $11807(2.42 \%)$ & $<0.0001$ \\
\hline \multicolumn{6}{|l|}{$35-49$ years } \\
\hline$<18.5$ & 11909 (5.77\%) & $2389(5.71 \%)$ & $6043(5.90 \%)$ & 3477 (5.60\%) & 0.0280 \\
\hline $18.5-23.9$ & $146221(70.85 \%)$ & 30644 (73.19\%) & $71454(69.81 \%)$ & $44123(71.00 \%)$ & $<0.0001$ \\
\hline $24-27.9$ & $39376(19.08 \%)$ & $7161(17.10 \%)$ & $20285(19.82 \%)$ & $11930(19.20 \%)$ & $<0.0001$ \\
\hline$\geq 28$ & $8864(4.30 \%)$ & $1679(4 \%)$ & $4575(4.47 \%)$ & $2610(4.2 \%)$ & $<0.0001$ \\
\hline
\end{tabular}

risk factor for PTB $;{ }^{5}{ }^{19}$ however, the results regarding the association between prepregnancy maternal obesity and incidence of PTB seem contradictory. ${ }^{20}{ }^{21}$ Our findings indicate that maternal underweight prior to pregnancy significantly elevated the risk for PTB, and obesity presented a marginally significant risk for PTB. There are two important potential mechanisms by which obesity may contribute to PTB: Foremost, obesity is a well-known risk factor for metabolic disorders such as diabetes mellitus and hypertension, which might be a reason for the observed increased risk for PTB. ${ }^{22}$ Researchers have also found that the risk was consistent in a sample of obese women without hypertensive disorders, diabetes and preterm delivery. ${ }^{23}$ Additionally, infection and inflammation have been indicated in PTB; it has been suggested that the level of proinflammatory cytokine was increased in circulation, particularly in obese pregnancy women. ${ }^{19} 23$

Low prepregnancy BMI may be an indication of poor maternal nutritional status. Women deficient in certain nutritional elements were susceptible to chronic infection and inflammation, which lead to an elevation in their risk for PTB. ${ }^{24}$ Maternal malnutrition has been associated with a reduction in placental weight and surface area. Low placenta weight and area decrease the transfer of nutrients and waste between maternal to fetal circulations, as well as restrict other normal processes of fetal growth and development. ${ }^{25}$ Thus, the chronic nutritional deficiency may also lead to LBW. Furthermore, some studies have shown that placental insufficiency was associated with maternal prepregnancy obesity. ${ }^{23}$ In this study, prepregnancy underweight, overweight and obese women have an increased risk of LBW. The association between LBW and underweight was consistent with previous studies, ${ }^{26}{ }^{27}$ while the risk of giving birth to a LBW infant decreased with an increasing prepregnancy BMI was presented by other studies. ${ }^{26} 28$

Associations between high or low BMI and SM have been previously evaluated in several reports. In our study, both prepregnancy obese and underweight women have a higher risk of spontaneous abortion, consistent with the earlier findings. ${ }^{29}{ }^{30}$ The SM rate of overweight women is similar to that of women with normal weight. Accumulating evidence showed that leptin is a hormone secreted mainly by adipose cells, and it plays an important role in the regulation of body weight. Leptin has a pivotal role among hormones governing metabolism and growth metabolically demanding situations, such as pregnancy. A slightly increased serum leptin level has been suggested to be beneficial during pregnancy. ${ }^{31}$ The level of serum leptin is associated with BMI; a mild increase in BMI can lead to a mild increase in leptin concentrations. However, an overincrease in BMI may lead to leptin resistance and other relative
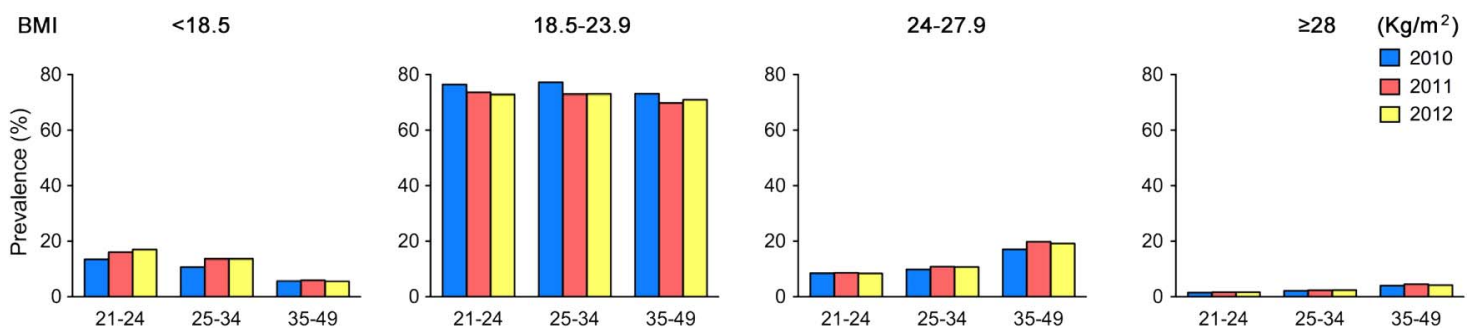

Figure 2 Trends of prepregnancy body mass index (BMI) in age-stratified subgroups during $2010-2012$. 
Table 4 Prepregnancy sociodemographic characteristics of 536098 pregnant women

\begin{tabular}{|c|c|c|c|}
\hline Variables & $\mathrm{N}(\%)$ & Prepregnancy BMI $\left(\mathrm{kg} / \mathrm{m}^{2}\right)^{\star}$ & p Value \\
\hline All & 536098 & $21.06 \pm 2.67$ & \\
\hline \multicolumn{3}{|l|}{ Age, years } & \multirow[t]{5}{*}{$<0.0001 \dagger$} \\
\hline $21-24$ & 134575 (25.10) & $20.78 \pm 2.53$ & \\
\hline $25-29$ & 265633 (49.55) & $20.88 \pm 2.59$ & \\
\hline $30-34$ & 100674 (18.78) & $21.54 \pm 2.83$ & \\
\hline $35-49$ & $35216(6.57)$ & $22.10 \pm 2.92$ & \\
\hline \multicolumn{3}{|l|}{ Ethnicity } & \multirow{3}{*}{$<0.0001 \ddagger$} \\
\hline Han & 507235 (94.62) & $21.06 \pm 2.67$ & \\
\hline Other & 28863 (5.38) & $21.14 \pm 2.71$ & \\
\hline \multicolumn{3}{|l|}{ Occupation } & \multirow[t]{4}{*}{$<0.0001 \dagger$} \\
\hline Farmer & 409344 (76.36) & $21.18 \pm 2.72$ & \\
\hline Factory worker & $52242(9.74)$ & $20.72 \pm 2.42$ & \\
\hline Other & 74512 (13.90) & $20.62 \pm 2.49$ & \\
\hline \multicolumn{3}{|l|}{ Educational level } & \multirow[t]{6}{*}{$<0.0001 \dagger$} \\
\hline None & $1125(0.21)$ & $21.46 \pm 2.89$ & \\
\hline Primary school & 23741 (4.43) & $21.42 \pm 2.96$ & \\
\hline Junior middle school & 351529 (65.57) & $21.23 \pm 2.70$ & \\
\hline Senior middle school & 104955 (19.58) & $20.72 \pm 2.52$ & \\
\hline University and more & $54748(10.21)$ & $20.47 \pm 2.44$ & \\
\hline \multicolumn{3}{|l|}{ Smoking } & \multirow[t]{3}{*}{$<0.0001 \ddagger$} \\
\hline No & 534278 (99.66) & $21.06 \pm 2.67$ & \\
\hline Yes & $1820(0.34)$ & $21.36 \pm 3.05$ & \\
\hline \multicolumn{3}{|l|}{ Drinking } & \multirow[t]{4}{*}{$<0.0001 \dagger$} \\
\hline No & 519894 (96.98) & $21.06 \pm 2.67$ & \\
\hline Casual & $16030(2.99)$ & $20.90 \pm 2.72$ & \\
\hline Often & $174(0.03)$ & $21.59 \pm 3.50$ & \\
\hline \multicolumn{3}{|l|}{ Previous pregnancy } & \multirow[t]{3}{*}{$<0.0001 \ddagger$} \\
\hline No & $351440(65.56)$ & $20.80 \pm 2.48$ & \\
\hline Yes & 184658 (34.44) & $21.55 \pm 2.94$ & \\
\hline \multicolumn{3}{|l|}{ Previous PTB } & \multirow[t]{3}{*}{$<0.00017$} \\
\hline No & 535067 (99.81) & $21.06 \pm 2.67$ & \\
\hline Yes & $1031(0.19)$ & $21.71 \pm 3.23$ & \\
\hline \multicolumn{3}{|l|}{ Previous SB } & \multirow[t]{3}{*}{$<0.0001 \ddagger$} \\
\hline No & 531855 (99.21) & $21.05 \pm 2.66$ & \\
\hline Yes & $4243(0.79)$ & $22.11 \pm 3.33$ & \\
\hline \multicolumn{3}{|l|}{ Previous SM } & \multirow[t]{3}{*}{$<0.0001 \ddagger$} \\
\hline No & 521864 (97.34) & $21.04 \pm 2.65$ & \\
\hline Yes & $14234(2.66)$ & $21.05 \pm 3.16$ & \\
\hline \multicolumn{3}{|l|}{ Previous birth defects } & \multirow[t]{3}{*}{$<0.0001 \ddagger$} \\
\hline No & 534348 (99.67) & $21.06 \pm 2.67$ & \\
\hline Yes & $1750(0.33)$ & $22.12 \pm 3.18$ & \\
\hline \multicolumn{4}{|c|}{$\begin{array}{l}\text { *Data are given as mean } \pm \text { SD. } \\
\text { †One-way analysis of variance. } \\
\text { †Student's t-test. } \\
\text { BMI, body mass index; PTB, pre }\end{array}$} \\
\hline
\end{tabular}

deficiencies. ${ }^{32}$ Some studies have suggested abnormally low serum leptin concentrations were detected in women who had a miscarriage. ${ }^{33}$ For these mechanisms, prepregnancy obesity and underweight might increase the risk of spontaneous abortion.

$\mathrm{SB}$ is a serious adverse fetal pregnancy outcome that has been linked to obesity. Our findings indicated that prepregnancy obese women were associated with a higher risk of SB (aOR 1.59; 95\% CI 1.18 to 2.15 ) compared with normal weight women. A population-based analysis studying 2868482 singleton births showed that overweight and obese women were more likely to experience SB compared with normal-weight women, and the risk of $\mathrm{SB}$ is elevated with ascending BMI values. ${ }^{34}$ These findings were evident in obese women without hypertensive disorders and diabetes. The higher risk of SB among obese women indicated that other mechanisms may be involved in the link between obesity and SB. ${ }^{35}$ To date, few studies have been conducted to investigate a possible relationship between obesity and EP. Our data suggested that obese prepregnant women were at a higher risk of developing EP. Further investigations are required to elucidate the mechanisms. 
Table 5 Crude and aORs for the association between BMI and each adverse pregnancy outcome

\begin{tabular}{|c|c|c|c|c|c|}
\hline Outcomes & Per cent ${ }^{\star}$ & Crude OR (95\% Cl) & p Value & aOR $(95 \% \mathrm{Cl})$ & p Value \\
\hline \multicolumn{6}{|l|}{ PTB $(n=6200)$} \\
\hline$<18.5$ & 15.13 & 1.16 (1.08 to 1.24$)$ & $<0.0001$ & 1.16 (1.08 to 1.25$)$ & $<0.0001$ \\
\hline $18.5-23.9$ & 73.24 & Ref & & Ref & \\
\hline $24-27.9$ & 9.48 & $1.03(0.94$ to 1.12$)$ & 0.5620 & $1.01(0.92$ to 1.10$)$ & 0.8940 \\
\hline$\geq 28$ & 2.15 & 1.21 (1.02 to 1.44$)$ & 0.0290 & $1.18(0.99$ to 1.4$)$ & 0.0640 \\
\hline \multicolumn{6}{|c|}{ LBW $(n=1909)$} \\
\hline$<18.5$ & 19.75 & $1.64(1.46$ to 1.84$)$ & $<0.0001$ & 1.57 (1.4 to 1.77$)$ & $<0.0001$ \\
\hline $18.5-23.9$ & 67.26 & Ref & & Ref & \\
\hline $24-27.9$ & 10.37 & 1.22 (1.05 to 1.42$)$ & 0.0090 & $1.22(1.05$ to 1.42$)$ & 0.0110 \\
\hline$\geq 28$ & 2.62 & $1.61(1.22$ to 2.14$)$ & $<0.0001$ & $1.60(1.2$ to 2.12$)$ & 0.0010 \\
\hline \multicolumn{6}{|c|}{$S M(n=15437)$} \\
\hline$<18.5$ & 13.96 & 1.07 (1.02 to 1.13$)$ & 0.0030 & $1.11(1.06$ to 1.17$)$ & $<0.0001$ \\
\hline $18.5-23.9$ & 72.79 & Ref & & Ref & \\
\hline $24-27.9$ & 10.85 & $1.18(1.12$ to 1.24$)$ & $<0.0001$ & $1.02(0.97$ to 1.08$)$ & 0.3680 \\
\hline$\geq 28$ & 2.4 & 1.37 (1.23 to 1.52$)$ & $<0.0001$ & $1.13(1.02$ to 1.26$)$ & 0.0210 \\
\hline \multicolumn{6}{|l|}{$\operatorname{EP}^{-}(n=441)$} \\
\hline$<18.5$ & 12.70 & 0.96 (0.73 to 1.28$)$ & 0.8030 & 1.09 (0.82 to 1.45$)$ & 0.5620 \\
\hline $18.5-23.9$ & 73.70 & Ref & & Ref & \\
\hline $24-27.9$ & 9.07 & $0.98(0.70$ to 1.35$)$ & 0.8800 & 0.74 (0.53 to 1.04$)$ & 0.0810 \\
\hline$\geq 28$ & 4.54 & 2.55 (1.62 to 4.01$)$ & $<0.0001$ & $1.78(1.13$ to 2.81$)$ & 0.0130 \\
\hline \multicolumn{6}{|l|}{$S B(n=1332)$} \\
\hline$<18.5$ & 12.84 & $1.00(0.85$ to 1.17$)$ & 0.9820 & 1.05 (0.89 to 1.24$)$ & 0.5400 \\
\hline $18.5-23.9$ & 72.00 & Ref & & Ref & \\
\hline $24-27.9$ & 11.76 & $1.30(1.10$ to 1.54$)$ & 0.0090 & $1.13(0.95$ to 1.34$)$ & 0.1640 \\
\hline$\geq 28$ & 3.38 & 1.94 (1.44 to 2.62$)$ & $<0.0001$ & $1.59(1.18$ to 2.15$)$ & 0.0030 \\
\hline
\end{tabular}

*Proportions of each adverse pregnancy outcome among four BMI categories.

aOR, adjusted OR; BMI, body mass index; EP, ectopic pregnancy; LBW, low-birth-weight; PTB, preterm birth; SB, stillbirth; SM, spontaneous miscarriage.

\section{Strengths and limitations of this study}

The strengths of this study are that we present evidence supporting the trends of prepregnancy BMI in the 3-year period and investigate relationships between maternal prepregnancy BMI groups and adverse pregnancy outcomes in a large population-based cohort. Furthermore, this is the largest national survey over the past 10 years offering an exploratory analysis of the relationship between prepregnancy BMI and pregnancy outcomes in China. One of the limitations of our study is the maternal prepregnancy BMI from the 3-year NFPHEP might be arguably and relatively inaccurate if conception occurred towards the end of 6 months after enrolment. This bias may yield inaccuracy when analysing the association between prepregnancy BMI and adverse pregnancy outcomes. Another limitation is that the majority of targeted women of childbearing age in the NFPHEP were from China's rural areas. How well this subpopulation represents the overall population requires further investigation.

\section{CONCLUSIONS}

Our data indicate there has been a decrease in the average prepregnancy BMI among women of childbearing age in rural China. Both extremely high and low maternal prepregnancy BMI have a significant association with the adverse pregnancy outcomes. Most notably, the prevalence of underweight individuals in a very large population significantly increases, and underweight prepregnant women have significant adverse pregnancy outcomes, likely because of nutrition deficiencies. Our work may raise awareness of the importance of preconceptional counselling for women in order to avoid adverse pregnancy outcomes.

\section{Author affiliations}

${ }^{1}$ Department of Obstetrics, The First Affiliated Hospital of Nanjing Medical University, Nanjing, China

${ }^{2}$ Department of Maternal \& Child Health, National Health and Family Planning Commission of the People's Republic of China, Beijing, China

${ }^{3}$ National Research Institute for Family Planning, Beijing, China

Contributors YP and SZ searched the literature, designed the study, analysed the data, interpreted the results and wrote the manuscript. QW, HS, YZ, YL and DY collected the data and revised the manuscript. LS conceived the study, designed the study, supervised the project, interpreted the results and revised the manuscript.

Funding This work was supported by Chinese Association of Maternal and Child Health Studies (AMCHS-2014-03).

Competing interests None declared.

Patient consent Obtained.

Ethics approval The study was approved by the Institutional Review Board (IRB) of Chinese Association of Maternal and Child Health Studies.

Provenance and peer review Not commissioned; externally peer reviewed.

Data sharing statement No additional data are available. 
Open Access This is an Open Access article distributed in accordance with the Creative Commons Attribution Non Commercial (CC BY-NC 4.0) license, which permits others to distribute, remix, adapt, build upon this work noncommercially, and license their derivative works on different terms, provided the original work is properly cited and the use is non-commercial. See: http:// creativecommons.org/licenses/by-nc/4.0/

\section{REFERENCES}

1. Cnattingius S, Bergström R, Lipworth L, et al. Prepregnancy weight and the risk of adverse pregnancy outcomes. $N$ Engl J Med 1998;338:147-52.

2. Schummers L, Hutcheon JA, Bodnar LM, et al. Risk of adverse pregnancy outcomes by prepregnancy body mass index: a population-based study to inform prepregnancy weight loss counseling. Obstet Gynecol 2015;125:133-43.

3. Flegal KM, Carroll MD, Kit BK, et al. Prevalence of obesity and trends in the distribution of body mass index among US adults, 1999-2010. JAMA 2012;307:491-7.

4. Ruager-Martin R, Hyde MJ, Modi N. Maternal obesity and infant outcomes. Early Hum Dev 2010;86:715-22.

5. Ehrenberg HM, Dierker L, Milluzzi C et al. Low maternal weight, failure to thrive in pregnancy, and adverse pregnancy outcomes. Am J Obstet Gynecol 2003;189:1726-30.

6. Baeten JM, Bukusi EA, Lambe M. Pregnancy complications and outcomes among overweight and obese nulliparous women. Am J Public Health 2001;91:436-40.

7. Weiss JL, Malone FD, Emig D, et al. Obesity, obstetric complications and cesarean delivery rate-a population-based screening study. Am J Obstet Gynecol 2004;190:1091-7.

8. Khashan AS, Kenny LC. The effects of maternal body mass index on pregnancy outcome. Eur J Epidemiol 2009;24:697-705.

9. Sebire NJ, Jolly M, Harris JP, et al. Maternal obesity and pregnancy outcome: a study of 287,213 pregnancies in London. Int $J$ Obes Relat Metab Disord 2001;25:1175-82.

10. Bodnar LM, Siega-Riz AM, Simhan HN, et al. The impact of exposure misclassification on associations between prepregnancy BMI and adverse pregnancy outcomes. Obesity (Silver Spring) 2010;18:2184-90.

11. Ding $\mathrm{XX}, \mathrm{Xu} \mathrm{SJ}$, Hao JH, et al. Maternal pre-pregnancy BMI and adverse pregnancy outcomes among Chinese women: results from the C-ABCS. J Obstet Gynaecol 2016;36:328-32.

12. Wei YM, Yang HX, Zhu WW, et al. Risk of adverse pregnancy outcomes stratified for pre-pregnancy body mass index. J Mater Fetal Neonatal Med 2016;29:2205-9.

13. Liu X, Du J, Wang G, et al. Effect of pre-pregnancy body mass index on adverse pregnancy outcome in north of China. Arch Gynecol Obstet 2011;283:65-70.

14. Zhang S, Wang Q, Shen H. [Design of the National Free Preconception Health Examination Project in China]. Zhonghua $Y i$ Xue Za Zhi 2015;95:162-5.

15. Sun $\mathrm{L}$, Wang $\mathrm{Q}$, Shen $\mathrm{H}$, et al. [Evaluation and trend analysis of prepregnancy nutrition in Chinese women of reproductive age during 2010-2012]. Zhonghua Yi Xue Za Zhi 2015;95:181-6.

16. Zhou BF, Cooperative Meta-Analysis Group of the Working Group on Obesity in China. Predictive values of body mass index and waist circumference for risk factors of certain related diseases in Chinese adults-study on optimal cut-off points of body mass index and waist circumference in Chinese adults. Biomed Environ Sci 2002;15:83-96.

17. Fisher SC, Kim SY, Sharma AJ, et al. Is obesity still increasing among pregnant women? Prepregnancy obesity trends in 20 states, 2003-2009. Prev Med 2013;56:372-8.

18. Ma GS, Li YP, Wu YF, et al. [The prevalence of body overweight and obesity and its changes among Chinese people during 1992 to 2002]. Zhonghua Yu Fang Yi Xue Za Zhi 2005;39:311-15.

19. Salihu HM, Mbah AK, Alio AP, et al. Low pre-pregnancy body mass index and risk of medically indicated versus spontaneous preterm singleton birth. Eur J Obstet Gynecol Reprod Biol 2009;144:119-23.

20. Chen Z, Du J, Shao L, et al. Prepregnancy body mass index, gestational weight gain, and pregnancy outcomes in China. Int J Gynaecol Obstet 2010;109:41-4.

21. Khatibi A, Brantsaeter AL, Sengpiel V, et al. Prepregnancy maternal body mass index and preterm delivery. Am J Obstet Gynecol 2012;207:212. e1-17.

22. Chatzi L, Plana E, Daraki V, et al. Metabolic syndrome in early pregnancy and risk of preterm birth. Am J Epidemiol 2009;170:829-36.

23. Huang L, Liu J, Feng L, et al. Maternal prepregnancy obesity is associated with higher risk of placental pathological lesions Placenta 2014;35:563-9.

24. Allen LH. Biological mechanisms that might underlie iron's effects on fetal growth and preterm birth. J Nutr 2001;131:581S-9S.

25. Lechtig A, Yarbrough $\mathrm{C}$, Delgado $\mathrm{H}$, et al. Effect of moderate maternal malnutrition on the placenta. Am J Obstet Gynecol 1975;123:191-201.

26. Liu Y, Dai W, Dai X, et al. Prepregnancy body mass index and gestational weight gain with the outcome of pregnancy: a 13-year study of 292,568 cases in China. Arch Gynecol Obstet 2012;286:905-11.

27. Li N, Liu E, Guo J, et al. Maternal prepregnancy body mass index and gestational weight gain on pregnancy outcomes. PLOS ONE 2013;8:e82310.

28. La Merrill M, Stein CR, Landrigan $\mathrm{P}$, et al. Prepregnancy body mass index, smoking during pregnancy, and infant birth weight. Ann Epidemiol 2011;21:413-20.

29. Metwally M, Ong KJ, Ledger WL, et al. Does high body mass index increase the risk of miscarriage after spontaneous and assisted conception? A meta-analysis of the evidence. Fertil Steril 2008;90:714-26.

30. Arck PC, Rücke $\mathrm{M}$, Rose $\mathrm{M}$, et al. Early risk factors for miscarriage: a prospective cohort study in pregnant women. Reprod Biomed Online 2008;17:101-13.

31. Casabiell X, Piñeiro V, Vega $F$, et al. Leptin, reproduction and sex steroids. Pituitary 2001;4:93-9.

32. Moschos S, Chan JL, Mantzoros CS. Leptin and reproduction: a review. Fertil Steril 2002;77:433-44.

33. Lage M, Garcia-Mayor RV, Tomé MA, et al. Serum leptin levels in women throughout pregnancy and the postpartum period and in women suffering spontaneous abortion. Clin Endocrinol (Oxf) 1999;50:211-16.

34. Yao R, Ananth CV, Park BY, et al. Obesity and the risk of stillbirth: a population-based cohort study. Am J Obstet Gynecol 2014;210:457. e1-9.

35. Salihu HM. Maternal obesity and stillbirth. Semin Perinatol 2011;35:340-4. 